\title{
Ecosistema digital durante la COVID-19: nueva normalidad, desescalada y desconfinamiento
}

\section{The digital ecosystem during the COVID-19 crisis: new normality and lockdown easing and lifting}

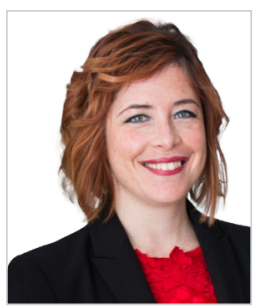

Lucia Ballesteros-Aguayo. Doctora en Periodismo con una tesis doctoral sobre la prensa durante el franquismo en España que obtuvo la máxima puntuación, Sobresaliente Cum Laude. Actualmente es profesora de la Universidad de Sevilla y colabora en tareas de investigación con diferentes entidades internacionales como el Instituto Nacional de Documentación, Innovación e Investigación en Educación, INDIRE, de Florencia (Italia) o el DigiMedia Research Centre de la Universidad de Aveiro (Portugal). Ha realizado varias estancias de investigación en el extranjero y tiene una amplia producción científica sobre historia del periodismo, propaganda política, posverdad, efectos de la comunicación, donde podemos destacar "Humour in the post-war press: Short stories of Gloria Fuertes in the falangist magazine Maravillas" en Revista Latina de Comunicación Social o "Traitors of the Homeland: The stigmatization of reds in falangist discourse" en Peter Lang.

Universidad de Sevilla, España

Iballesteros@us.es

ORCID: 0000-0003-1191-4070

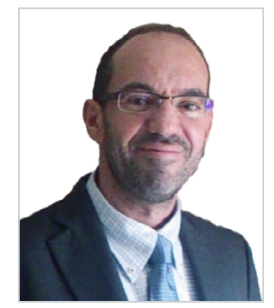

Francisco Javier Escobar Borrego. Doctor en Filología hispánica, desarrolla su labor profesional como Profesor Titular de Literatura Española en la Facultad de Filología de la Universidad de Sevilla. Ha dedicado estudios de investigación al pensamiento estético y a la obra de los autores de oro, con especial énfasis en el Humanismo. En cuanto a sus investigaciones sobre la literatura española contemporánea, desde el compartimento y la historia de las mentalidades, ideas o representaciones, se ha centrado en estudios dedicados al pensamiento conceptual. Entre algunos de los premios y reconocimientos que se le han concedido, destaca el Premio Internacional José de Vasconcelos, el Premio legado José Vallejo y el Premio Extraordinario de Doctorado.

Universidad de Sevilla, España

fescobar@us.es

ORCID: 0000-0001-5400-2712

Recibido: 15/07/2020 - Aceptado: 02/11/2020

Resumen:

El presente trabajo centra su objeto en el estudio de la variabilidad lingüística, conceptual y normativa derivada de la emergencia sanitaria producida por la súbita aparición de la enfermedad COVID-19, y la veloz transmisión de esa variabilidad favorecida por las nuevas tecnologías de la información y comunicación que permiten incluir novedosas narrativas periodísticas y comunicativas. Así constatamos que a raíz de la emergencia sanitaria se ha multiplicado el empleo de las plataformas digitales al tiempo que se ha avanzado en la implantación de la sociedad en red. Meto-
Received: 15/07/2020 - Accepted: 02/11/2020

\section{Abstract:}

The main aim of this paper is to examine some of the linguistic, conceptual and normative variations, resulting from the public health emergency triggered by the COVID-19 disease, and their rapid spread thanks to new information and communication technologies. Consequently, these technologies have allowed for the shaping of new journalistic and communication narratives. Indeed, as a result of the public health emergency it has been possible to confirm both the greater use of digital platforms and the consolidation of the network society. As to the study methodology, two procedures were

Cómo citar este artículo:

Ballesteros-Aguayo, L.; Escobar Borrego, F. J. (2020). Ecosistema digital durante la COVID-19: nueva normalidad, desescalada y desconfinamiento. Doxa Comunicación, 31, pp. 341-360.

https://doi.org/10.31921/doxacom.n31a17 
dológicamente utilizaremos dos procedimientos, uno deductivo en el que estableceremos el marco teórico que sustenta la fluidez, permeabilidad y flexibilidad del lenguaje para adaptarse a novedosas situaciones, y otro inductivo en el que, partiendo de las categorías conceptuales emergentes, esbozaremos la implementación de un corpus de palabras que posiblemente muchas de ellas queden incorporadas en el campo léxico de los hablantes en virtud de su cooperación interactuante en el ecosistema digital. En paralelo, nos detendremos en el análisis descriptivo, cualitativo y etimológico de tres nuevos eufemismos (nueva normalidad, desescalada $y$ desconfinamiento) que tienen un marcado carácter terminal de la crisis sanitaria y que poseen una consideración paradigmática para futuras investigaciones.

Palabras clave:

COVID-19; ecosistema digital; nueva normalidad; desescalada; desconfinamiento. employed: on the one hand, a deductive method for establishing the theoretical framework in order to analyse the fluidity, permeability and flexibility of language in this new situation; and, on the other, an inductive method, based on emerging conceptual categories, for creating a corpus of words, many of which will probably be incorporated into the lexicon of the citizenry owing to their interaction in the digital ecosystem. Specifically, the focus will be placed here on a descriptive, qualitative and etymological analysis of three new euphemisms ('new normality', 'lockdown easing' and 'lockdown lifting'), due to their strong association with the end of public health crisis and to the fact that they may well be considered as paradigmatic for future research.

\section{Keywords:}

COVID-19; digital ecosystem; new normality; lockdown easing; lockdown lifting.

\section{Introducción. Fundamentación teórica}

La lengua se erige como un sistema vivo y flexible que evoluciona y se adapta a los diferentes entornos sociales dentro de una comunidad de hablantes conforme a la aparición de nuevos acontecimientos sociales y renovados entornos comunicativos.

Ello se desprende de las formulaciones de diversos analistas clásicos del lenguaje que podrían considerarse los padres de la lingüística general y defensores de esa capacidad adaptiva del lenguaje natural. Sobre este pilar descansa la visible conexión existente entre esa capacidad en virtud de la creación de nuevos conceptos, y su paulatina implementación ante la novedosa realidad surgida de la pandemia universal de la enfermedad COVID-19. Asimismo, no cabe olvidar a este respecto la palmaria difusión de estos conceptos a través de las plataformas comunicativas como tampoco la lexicalización (es decir, la incorporación diacrónica en el léxico de nuestra lengua) de determinados conceptos y expresiones que han aflorado a partir de una nueva cosmovisión intelectiva y vivencial.

En efecto, una de las características esenciales que diferencian al ser humano de otros seres que pueblan y cohabitan el universo viene dada por la capacidad de comunicarse en virtud de un lenguaje articulado (Chomsky, 1992). Tanto es así que, por su capacidad simbólica, interconectamos hechos simples con el propósito de construir otros de naturaleza más compleja y sutil que nos darán como resultado el universo de sentido que llamamos mundo, y que conocemos y transmitimos a través de las palabras que comparten todos los hablantes de un mismo idioma.

Y es que desde que Saussure introdujera la dicotomía fundamental entre lengua y habla, numerosas han sido las modificaciones en el esquema básico a nivel diacrónico tras los avances de la lingüística general, las ciencias de la información, la robótica y la inteligencia artificial, entre otras disciplinas y líneas matrices de investigación. 
Pues bien, la lengua solo atesora sentido en el seno de determinados hablantes que la materializan gracias a sus actos, por lo que el habla es el uso que ellos hacen de la lengua en un lugar y tiempo determinados. Lengua y habla, en suma, guardan reciprocidad, de forma que la lengua lo es por mor del habla y viceversa, y solo tienen sentido en esa estructura dicotómica.

Este esquema un tanto rígido fue modificado según Coseriu (1962) por Hjelmslev y Lotz en la denominada por Coseriu "Conferencia semántica" en 1951 en la que introducían la tríada sistema-norma-habla. En palabras de Coseriu (1962: 11):

[...] los profesores Hjelmslev, de Copenhague, y Lotz, de Nueva York (semantistas «intrínsecos» y representantes, en la conferencia, de la «dirección integral de la gramática general»), presentaron su posición resumida en un cuadro en el cual aparece la distinción de tres aspectos en el lenguaje -esquema, norma establecida y parole (habla)-, en lugar de los dos ya tradicionales en la lingüística postsaussureana (aun en la que no acepta la doctrina del maestro ginebrino): langue y parole, lengua y habla (Sprache-Rede, language-speech).

Para ellos, en resumidas cuentas, el punto de intersección entre la lengua y el habla viene dado por el acto verbal.

Ahora bien, estas concepciones relacionadas con la parole, en el transcurso del tiempo fueron objeto de múltiples y aceradas controversias, por lo que recientemente -eso sí, salvando las diferencias- destacados filósofos del lenguaje como Austin (1975) prefiere hablar de 'realizativos', Searle (1980) de 'actos de habla' y, en fin, Acero (1989) señala las proferencias en general para referirse a "[...] cualquier acto verbal consistente en la emisión (bien por medio de nuestro aparato fonador, bien por algún medio mecánico) o en la inscripción de un signo o conjunto de signos” (Acero et al., 1989: 33).

De una forma u otra, lo verdaderamente importante es que las reglas por las que se rige el hablante no son rígidas ni constriñen la comunicación, sino que la favorecen y permiten modificaciones que no alteran la esencia de la comprensión del mensaje, como afirma Coseriu (1962: 107):

En efecto, hemos visto que lo que se impone al hablante no es el sistema (que «se le ofrece»), sino la norma. Ahora bien, el hablante tiene conciencia del sistema, y lo utiliza, y, por otro lado, conoce o no conoce, obedece o no obedece la norma, aun manteniéndose dentro de las posibilidades del sistema [...] De esta manera, el individuo hablante aparece como punto de partida también del cambio en el sistema, que empieza por el desconocimiento o la no-aceptación de la norma.

La capacidad creativa del hablante y, por ende, de la lengua es ilimitada para adaptarse a distintos entornos y favorecer de esta forma la comunicación.

En otras palabras, la comunicación solo resulta posible en términos de comprensión, por lo tanto, nos remite a profundizar en la interpretación como resultado del llamado giro lingüístico que autores como Gadamer (1998), Palmer (2002) y Lledó (2015) sostienen como claves axiales para interpretar las palabras escritas desde una línea hermenéutica; ciertamente el interés de estos autores va dirigido al discurso escrito, no a su carácter de oralidad, porque:

Hermenéutica es el arte de entender, y el objeto de ese entender es el discurso escrito. Frente al discurso oral que agota la temporalidad en su fluencia, en su sucesiva y efímera simultaneidad, el escrito pierde, en cierto sentido, el carácter de inmediatez, eso que la filosofía analítica ha denominado lo ilocucionario, para insertarse en un ambiguo sistema de perlocución (Lledó, 2015: 49). 
Lo importante, en cualquier caso, es que para comprender un fenómeno o hecho concreto, este se halla ligado al significado y no, en cambio, a la proferencia, con la que puede incluso no coincidir: "La comunicación humana es, para empezar, una continuada sucesión, un constante intercambio de proferencias, de actos verbales que se caracterizan por la importante propiedad de ser significativos, de poseer un significado, una clave cuyo conocimiento garantiza su comprensión" (Acero et al., 1989: 33-34).

Por tanto, la tradicional diferencia entre uso (la emisión) y mención (usamos una palabra no para referirnos a ella misma) nos sitúa ante el problema del significado que tantas discusiones ha suscitado hasta la fecha entre los lingüistas y los filósofos del lenguaje (Chomsky: 1992). De hecho, numerosos han sido los esfuerzos en aras de esclarecer las relaciones complejas que subyacen al significado habida cuenta de que los intentos son muy variados hasta el punto de que van desde el psicologismo semántico de Platón contenido en la Carta VII, su posterior rechazo por Frege (1971), hasta Hempel (1966) y Quine (1962), pasando por una extensa bibliografía. Operativamente suscribimos la síntesis que brinda Geoffrey Leech (1977: 15):

La palabra «significado» y su verbo correspondiente, «significar», se encuentran decididamente entre los términos más controvertidos de nuestro idioma; parece que los semantistas han consumido frecuentemente un tiempo excesivo en descifrar los «significados del significado», como un preliminar supuestamente necesario para el estudio de su tema. El libro quizás más conocido que se haya escrito nunca sobre semántica, el que publicaron O. K. Ogden e I. A. Richards en 1923, tenía precisamente como título The Meaning of Meaning [El significado del significado], y contenía -en las páginas 186-7- una lista de nada menos que veintidós definiciones (desde diversos puntos de vista teoréticos y no teoréticos) de la palabra en cuestión.

Leech (1977: 15-16), en particular, subraya algunas definiciones de significado que nos servirán funcionalmente en nuestra investigación y nos ayudarán a comprender la cosmovisión que genera en los hablantes. Con ese fin destacamos:

1. Las palabras que se adjuntan a una palabra del diccionario.

2. La connotación de una palabra.

3. Una propiedad intrínseca.

4. Las consecuencias prácticas que para nuestra experiencia futura reviste una cosa.

5. Aquello a lo que interpreta un símbolo:

a. Aquello a lo que se refiera.

b. Aquello a lo que crea referirse.

c. Aquello que crea que se refiere el que lo utiliza

\subsection{Eufemismos}

En el análisis del vocabulario identificable y reconocible en el proceso de la pandemia en lo que se refiere a la formación de eufemismos, seguiremos la clasificación que acertadamente hace Chamizo Domínguez en su artículo "La función social y cognitiva del eufemismo y del disfemismo” publicado en Panace@. Boletín de Medicina y Traducción en 2004. 
Chamizo, en síntesis, considera los eufemismos y disfemismos como ejemplos particulares de metáforas en virtud de las cuales se produce una transferencia de propiedades de una cosa a otra que no la posee, pero su empleo masivo tiende a una modificación léxica que crea de esta suerte campos semánticos y familias de palabras. De modo similar a lo que sucede en el proceso de la creación literaria y poética cuando en el marco de la poiesis el escritor o el poeta intenta expresar lo inefable recurriendo a la creación de metáforas, ocurre con el eufemismo, aunque desligado de su aspecto estético.

Además Chamizo (2004: 45) destaca la primacía del uso para la perpetuación del eufemismo:

El que una palabra dada (o una expresión, en su caso) sea sentida por los hablantes como un eufemismo o como un disfemismo no depende de la palabra en sí, sino del contexto, del uso que se haya hecho de dicha palabra o de las intenciones de los hablantes.

Chamizo, en particular, afirma que la falta de cooperación puede dar lugar a chistes o variadas formalizaciones literarias a partir de un manifiesto proceso de ficcionalización. Sea como fuere, partiendo de tales análisis nos interesa destacar una característica axial por ser verdaderamente relevante para nuestro objeto de estudio: la cooperación necesaria de los hablantes.

Por otra parte, examinamos la triple clasificación propuesta por Chamizo (2004: 46) a propósito del origen de los eufemismos: novedosos, semilexicalizados y lexicalizados.

Los primeros, llamados eufemismos novedosos son aquellos que se crean "en un momento dado sin que pertenezca a ninguna red conceptual previa y sin que fuera predecible a priori, pero que, sin embargo, es comprendido por los oyentes que conocen el contexto en que se ha creado".

Los segundos, semilexicalizados, son los que han entrado a formar parte del acervo de una lengua y "es utilizado y comprendido como tal de forma habitual por los hablantes de una lengua, pero en el que es posible aún distinguir el significado literal y el significado eufemístico de un término o de una colocación".

Por último, los eufemismos lexicalizados o "muertos" son "aquéllos para los que los hablantes han perdido la conciencia de su origen eufemístico porque se ha perdido la conciencia del significado literal original de la palabra en cuestión".

Consideraremos en este estudio solo los dos primeros y dejaremos para otro trabajo de investigación los eufemismos lexicalizados, puesto que los eufemismos incluidos en nuestro análisis se encuentran en proceso en medio de la crisis sanitaria que hoy aún padecemos.

En resumidas cuentas, para que un eufemismo se lexicalice precisa de una perspectiva histórica y de la necesaria cooperación de los hablantes.

\subsection{Juegos lingüísticos}

Cualquier hablante tiene integradas o incorporadas en su mente tanto las reglas de formación de oraciones como las propiedades de su significado correspondiente. Ahora bien, pueden intervenir, a modo de contrapunto, condicionantes extralingüísticos que favorezcan, en contraste, una ejecución desviada de la norma provocada por creencias, por la estructura cognoscitiva del hablante e incluso por mermas de la memoria. Chomsky $(1975,1992)$, en concreto, parte de 
la idea de que el uso normal del lenguaje es ilimitado, por lo que puede producir y formar nuevas oraciones arbitrarias complejas.

A ello debemos añadir la concepción de Wittgenstein considerada como un positivismo terapéutico y preponderante en la escuela de Cambridge. Para Wittgenstein según el Diccionario de Filosofía de José Ferrater Mora (1981)
[...] "el lenguaje puede ser comparado a un juego; hay tantos lenguajes como juegos de lenguaje. Por tanto, entender una palabra en un lenguaje no es primariamente comprender su significación, sino saber cómo funciona, o cómo se usa, dentro de uno de esos «juegos».

Al margen de la lógica formal, estima que el lenguaje no representa individuos o hechos, este es solo uno de los usos, sino que es básicamente un sistema de actividades en tanto que el significado se encuentra ligado a lo que denomina "juegos lingüísticos”; y procede así para referirse a las distintas formas de emplear los recursos lingüísticos ligados a diferentes situaciones comunicativas propias de formas de vida distintas. Basta con distinguir, en suma, el lugar natural que ocupan los términos o las proposiciones para comprender su significado. Incluso Javier Sádaba (1980: 119), en Conocer Wittgenstein y su obra, lo explica del siguiente modo:

Los juegos de lenguaje son el locus del significado $(49,116,261)$. ¿Qué quiere decir esto? Que la relación entre las proposiciones y los estados de cosas se hace, ahora, por medio de los juegos de lenguaje. Son lo último.

Continúa caracterizando este investigador los juegos de lenguaje como indefinibles, cambiantes, abiertos e incalculables. Ciertamente, afirma que, existen reglas, pero solo como un constructo abstracto que se necesita para la comunicación, dado que son arbitrarias y convencionales al tiempo que se aprenden en las reacciones de las personas ante los acontecimientos acaecidos. El lenguaje, por último, estará en función de nuestras necesidades e intereses y sus reglas consistirán en una práctica humana.

\subsection{Analogías}

Uno de los procedimientos de la formación y la aparición de nuevos usos y significados de palabras se encuentra en la raíz de las analogías.

Tal y como recoge Ferrater Mora (1981), la analogía se refiere a

[...] la correlación entre los términos de dos o varios sistemas u órdenes, es decir, la existencia de una relación entre cada uno de los términos de un sistema y cada uno de los términos de otro. La analogía equivale entonces a proporción, la cual puede ser entendida cuantitativa o topológicamente. Se ha hablado también de analogía como semejanza de una cosa con otra, de la similitud de unos caracteres o funciones con otros. En este último caso la analogía consiste en la atribución de los mismos predicados a diversos objetos [...].

Asimismo, el análisis primigenio y prístino más detallado del concepto de analogía lo encontramos en el Órganon de Aristóteles en la concepción tripartita de los términos que clasifica en:

1. Unívocos: son aquellos que significan un solo concepto y se utilizan en el mismo sentido. 
2. Equívocos: son términos que expresan conceptos completamente distintos y, por lo tanto, se emplean en diversos sentidos.

3. Análogos: son términos que, aunque expresan conceptos distintos, no son completamente distintos sino solo en cierta proporción.

Aristóteles (1982: 151-2), de hecho, ya había empleado esta relación de analogía para referirse a la noción de "ser" de la metafísica, la cual ni es unívoca ni es equívoca, sino que es análoga, porque

El Ente se dice en varios sentidos, aunque en orden a una sola cosa y a cierta naturaleza única, y no equívocamente, sino como se dice también todo lo sano en orden a la sanidad: esto porque la conserva; aquello, porque la produce, lo otro porque es signo de sanidad, y lo de más allá, porque es capaz de recibirla; y lo medicinal se dice en orden a la medicina (pues esto se dice medicinal porque tiene el arte de la medicina; lo otro, por estar bien dispuesto por naturaleza para ella, y lo de más allá, por ser obra de la medicina); y de manera semejante a éstas hallaremos que se dicen también otras cosas.

\section{Ecosistema digital. Transmedia}

La interacción interdigital de los flujos comunicativos en las plataformas de redes sociales (Web 2.0, 3.0 y 4.0) desempeña un papel relevante para que se complete el proceso de lexicalización de un eufemismo. Particularmente la plataforma Web 2.0 ha promovido con intensidad la cooperación para transmitir, recrear, implementar e incluso tergiversar la terminología novedosa. La también llamada "web social” según Wikipedia

[...] comprende aquellos sitios web que facilitan compartir información, la interoperabilidad, el diseño centrado en el usuario y la colaboración en la World Wide Web. Web 2.0 permite a los usuarios interactuar y colaborar entre sí, como creadores de contenido. La red social conocida como web 2.0 pasa de ser un simple contenedor o fuente de información; la web en este caso se convierte en una plataforma de trabajo colaborativo. Ejemplos de la Web 2.0 son las comunidades web, los servicios web, las aplicaciones Web, los servicios de red social, los servicios de alojamiento de videos, las wikis, blogs, mashups y folcsonomías.

De esta manera, el entramado transmedia digital cuyo punto principal es la web social se ha convertido en una auténtica revolución comunicativa al introducir la narrativa o ecosistema digital, es decir, la capacidad para transmitir información por diferentes sistemas y webs. A partir del uso generalizado de Internet, el correo electrónico, los blogs, las wikis, las redes sociales como Twitter, Facebook, o Linkedin,

[...] cada persona se ha convertido en su propio editor/a, en su propio medio de comunicación a través de sus cuentas en Twitter, Instagram, Whatssapp, Telegram, Tumblr o cualquier plataforma de blogs. Como consecuencia de esta hiperconectividad una noticia, falsa o no, puede hacerse viral en función de su contenido debido a este ecosistema característico del mundo en el que vivimos (Bandrés, Badillo y Ramos, 2018: 161).

Este ecosistema y sus derivados se han erigido en auténticos entornos virtuales, aunque no siempre virtuosos, en los que se comparte la información gracias a que los componentes de la "web social" han hecho realidad la fluidez y el dinamismo en la transmisión de información. A ello hay que añadir, claro está, que la conectividad se ha visto reforzada más si cabe 
por videoconferencia en virtud de diversas opciones, a saber, plataforma WhatsApp o las aplicaciones telemáticas como Zoom o Skype, entre otras, que permiten reuniones virtuales con usos diversos, incluso educativos, y que vienen manteniendo hasta el momento un papel relevante en el nuevo paradigma comunicativo. Es más, la incansable industria digital en vías de desarrollo trabaja en la progresiva implantación y aclimatación generalizada de la web 4.0 en la que priman los asistentes virtuales como Alexa de Amazon o Siri de Apple, que preconizan la total implementación del lenguaje natural a la robótica con la aplicación de mensajes orales con respuesta similar a la de los humanos.

\section{Conceptualizaciones novedosas durante la COVID-19}

La diferencia establecida por Chomsky $(1975,1992)$ entre competencia y ejecución junto a la concepción del significado como juego lingüístico constituye el fundamento teórico sobre el que se asienta la caracterización de la lengua como un sistema vivo en el que la libertad de los hablantes les permite ampliar su acervo lingüístico recreando o creando nuevas palabras y expresiones en función de sus necesidades, su creatividad y el entorno social. De este modo, encontramos que situaciones novedosas en el entorno social de los hablantes producen actos creativos del habla.

En el caso de nuestro estudio, el vocabulario difundido durante la crisis sanitaria de la enfermedad COVID-19 ha sido analizado en función de dos vectores: su génesis formativa a la que le añadiremos el análisis semántico-pragmático de signos-tipo habida cuenta de los contextos de uso.

En primer lugar, considerando la génesis formativa de este vocabulario podemos señalar algunas características comunes que recogemos en la siguiente tabla:

Tabla 1. Características comunes del vocabulario de la COVID-19 en las plataformas digitales

Características comunes del vocabulario de la COVID-19 difundido en las plataformas digitales.
1) La mayoría son eufemismos por analogía o expresiones eufémicas inconsistentes.

2) Entroncan con un vocabulario sanitario técnico.

3) Provienen de instancias de variables matemáticas.

4) Aluden por sus rasgos sémicos a instancias bélicas.

5) Implican positividad inmediata.

6) Se difunden masivamente.

7) Entran a formar parte del vocabulario común con independencia de que los reconozca la RAE y de que terminen lexicalizándose.

8) Presentan y denotan un sesgo ideológico tendente a una visión esperanzadora de los resultados.

9) Implican en la mayoría de los casos superación, progreso, rebasamiento y libertad.

10) Tienen como finalidad trasladar una sensación de control para atenuar y contrarrestar una situación penosa y precaria.

Fuente. Elaboración propia 
Aunque reconocemos la incapacidad para llevar a cabo una síntesis comprensiva de los procesos formativos de nueva terminología en un proceso actualmente en evolución y por ello forzosamente incompleto, la clasificación de los procesos formativos reviste, sin mayores pretensiones, una finalidad preparatoria o exploratoria. En cualquier caso, nuestro estudio se centrará en los más frecuentes que son la creación de eufemismos, analogías y lenguaje usado en el contexto digital:

Tabla 2. Aproximaciones exploratorias de variaciones lingüísticas normativas para un posible corpus léxico durante la pandemia de la enfermedad COVID-19

\begin{tabular}{|c|c|c|}
\hline \multirow{7}{*}{$\begin{array}{l}\text { Aproximaciones exploratorias } \\
\text { de variaciones lingüísticas } \\
\text { normativas para un posible corpus } \\
\text { léxico durante la pandemia de la } \\
\text { enfermedad COVID-19. }\end{array}$} & & $\begin{array}{l}\text { La circunlocución: "nueva normalidad" para referirse al futuro; "pico de pandemia" para } \\
\text { aludir al máximo; "distancia social" para designar separación. }\end{array}$ \\
\hline & 2) & Analogías con el alpinismo: "desescalada" y "pico de pandemia”. \\
\hline & 3) & $\begin{array}{l}\text { Correspondencias que atañen a la terminología sanitaria: "pico de pandemia", "supercon- } \\
\text { tagiadores", "COVID-19". }\end{array}$ \\
\hline & 4) & $\begin{array}{l}\text { Designaciones analógicas respecto a universales éticos como la libertad o la salvación: } \\
\text { "desconfinamiento", "Arcas de Noé". }\end{array}$ \\
\hline & 5) & $\begin{array}{l}\text { Correspondencias analógicas con variables matemáticas: "aplanar la curva" o "crecimiento } \\
\text { exponencial". }\end{array}$ \\
\hline & 6) & $\begin{array}{l}\text { Lenguaje de las Redes Sociales, eslóganes, etiquetas: \#YoMeQuedoEnCasa \#EsteVirusLo- } \\
\text { ParamosUnidos }\end{array}$ \\
\hline & & $\begin{array}{l}\text { Neologismos, COVID-19, otros con implicaciones musicales, así en lo que hace a la compo- } \\
\text { sición de acordes: "clúster". }\end{array}$ \\
\hline
\end{tabular}

Fuente. Elaboración propia

La selección de los conceptos que analizaremos a continuación (nueva normalidad, desescalada y desconfinamiento) atiende a un criterio finalista como posible resolución de la crisis sanitaria, y también a su valor paradigmático como modelos para otros términos eufémicos análogos.

\section{Análisis semántico-pragmático de signos-tipo terminales paradigmáticos: "nueva normalidad", “desescalada” y “desconfinamiento"}

Tal como señalamos en el fundamento teórico de este trabajo para el análisis de la terminología seleccionada seguiremos la orientación sugerida por Leech (1977), y así procederemos en primer lugar a buscar las definiciones que arroja el diccionario, y en segundo lugar a delimitar el componente pragmático.

Con objeto de comprobar si los vocablos que estamos analizando han sufrido alguna evolución semántica diacrónica, consultaremos sus definiciones recurriendo a dos fuentes diversas primordiales: por un lado, el Diccionario Enciclopédico Universal de 1990, y por otro, el DEL en su versión de 2014. 


\subsection{La expresión nueva normalidad}

Con respecto a la búsqueda de los conceptos "nuevo" y "normal” el Diccionario Enciclopédico Universal (1990) en papel indica en relación al adjetivo "nuevo":

1. Que se ve o se oye por primera vez

2. Distinto o diferente de lo que antes había

3. Que sobreviene o se añade a una cosa que había antes

Y "normalidad" la define como calidad o condición de normal, por lo que si consultamos la definición de "normal" obtenemos:

1.- Se dice de lo que se halla en su estado natural

2.- Que se ajusta a ciertas normas fijadas de antemano

Junto a ello, también creemos pertinente resaltar la definición que ofrece el Diccionario de "normalizar", por su proximidad a la circunlocución "nueva normalidad":

1.- Regularizar y poner en buen orden lo que no estaba

Referente a la consulta llevada a cabo en el DLE on line (2014), encontramos que "nuevo" lo define como:

2. adj. Que se percibe o se experimenta por primera vez.

3. adj. Repetido o reiterado para renovarlo.

4. adj. Distinto o diferente de lo que antes había o se tenía aprendido.

5. adj. Que sobreviene o se añade a algo que había antes.

Y "normal" lo define como:

1. adj. Dicho de una cosa: Que se halla en su estado natural.

2. adj. Habitual u ordinario.

3. adj. Que sirve de norma o regla.

Del análisis comparativo de las dos fuentes consultadas podemos concluir:

1. Que "nuevo" mantiene diacrónicamente un significado próximo a "ser experimentado por primera vez", a diferencia de "lo que había antes".

2. Que "normal" mantiene diacrónicamente un carácter de normatividad regular que se relaciona con "lo natural", lo "ordinario".

Estas conclusiones nos resultan útiles para el análisis pragmático de la circunlocución "nueva normalidad" del que podemos destacar los siguientes rasgos: 
Tabla 3. Análisis pragmático de nueva normalidad

\begin{tabular}{|c|c|}
\hline \multirow{5}{*}{$\begin{array}{l}\text { Análisis pragmático de } \\
\text { nueva normalidad }\end{array}$} & $\begin{array}{l}\text { 1. El carácter reciente de "lo normal" implica positividad, variación inmediata en el sentido de volver } \\
\text { a recuperar un orden que se había perdido durante la crisis sanitaria, de ahí que contenga una com- } \\
\text { ponente positiva. Eso, unido al carácter de "lo nuevo" como lo recién hecho, recién incorporado, } \\
\text { crea en la intelección a la ciudadanía una tendencia a interpretar que lo cambiante en el plano social } \\
\text { impone una familiaridad de la que la sociedad en su conjunto ha carecido durante la pandemia. }\end{array}$ \\
\hline & $\begin{array}{l}\text { 2. La vuelta a lo normal, a las reglas naturales que siempre han estado vigentes tiene como finalidad } \\
\text { trasladar una sensación de control reglado con objeto de atenuar y contrarrestar la situación penosa } \\
\text { y precaria vivida con anterioridad por la orden de confinamiento del estado de alarma. }\end{array}$ \\
\hline & $\begin{array}{l}\text { 3. Volver a la "nueva normalidad", esta máxima señalada por las autoridades sanitarias presenta y de- } \\
\text { nota un sesgo ideológico con un peso desproporcionado a favor de quienes posibilitan la vuelta de la } \\
\text { ciudadanía a ese estado. En el contexto cultural se interpreta de forma tácita que la recuperación del } \\
\text { equilibrio de las formas pretéritas ordenadas, habituales y cotidianas son el resultado de la gestión } \\
\text { en la que se han impuesto medidas eficaces conducentes a una visión esperanzadora. }\end{array}$ \\
\hline & $\begin{array}{l}\text { 4. Implica una superación, un progreso, un rebasamiento de la anormalidad vivida durante el proceso } \\
\text { anterior y una vuelta a la libertad pretérita marcada por el orden y el equilibrio }\end{array}$ \\
\hline & 5. Se difunde masivamente a través del ecosistema digital. \\
\hline
\end{tabular}

Fuente. Elaboración propia

Según se recoge en la tabla 1. "Características comunes del vocabulario de la COVID-19 en las plataformas digitales" se trata de un eufemismo inconsistente.

La contradicción inherente de esta expresión plantea a los hablantes algunas dificultades de compresión, de ahí que sea uno de los motivos fundamentales que dificulte posiblemente su lexicalización en el vocabulario colectivo de los hispanohablantes habida cuenta de que requiere cooperación por parte de ellos.

En este caso, el absurdo de la unión de dos conceptos contradictorios ("nuevo" y "normal"), los configura ininteligibles en la medida en que son necesariamente falsos. Y es que, para poder hacer inteligible una contradicción, el oyente necesita modificar las reglas del lenguaje de un modo afín a como si se cambiasen las reglas del juego, salvando las distancias, en una competición deportiva. La ruptura normativa exige, por tanto, un esfuerzo extraordinario si tenemos presente que los enunciados absurdos los acaba rechazando nuestra mente. A decir de Leech (1977: 23):

Parece ser que un principio incontrovertible de la semántica es el de que el pensamiento humano aborrece el vacío de sentido; por ello, un hablante de nuestra lengua al que se le presenten oraciones absurdas exigirá un esfuerzo supremo a su facultad interpretativa hasta que logre hacérselas inteligibles [...].

Sin embargo, es plausible tanto desde la distinción chomskiana entre competencia y ejecución como desde la noción wittgensteiniana de juego lingüístico sugeridas en este trabajo, ya que tal deslinde nos permitirá alejarnos de cualquier concepción rígida que pudiera imponer inexorablemente un carácter de falsedad a toda innovación sintáctica o semántica. Esto es, en virtud de la competencia. 


\subsection{El vocablo desescalada}

El término "desescalada" está formado por la base léxica "escalar" a la que se le añade el afijo prefijo "des-". Los prefijos son partículas léxicas que, añadidas a una palabra, influyen en su significado aportando al individuo una cosmovisión concreta, que no poseería, en efecto, sin esa partícula.

Una de las clasificaciones de los afijos se refiere a su origen que los sitúa como procedentes del latín o procedentes del griego. Sobre este particular también el DLE (2014) ofrece una explicación acerca del origen del prefijo "des-":

Confluencia de los prefs. lats. de-, ex-, dis- y a veces e-.1. pref. Denota negación o inversión del significado de la palabra simple a la que va antepuesto. Desconfiar, deshacer.2. pref. Indica privación. Desabejar.3. pref. Indica exceso o demasía. Deslenguado. 4. pref. Significa 'fuera de’. Descamino, deshora. 5. pref. A veces indica afirmación. Despavorido.

También la NGLE (2009) establece que el prefijo añadido “des-” significa, entre otras cosas, 'privación', 'negación', además de 'volver al estado anterior'.

En este caso se ha añadido al verbo escalar que el Diccionario Enciclopédico Universal (1990) define como:

1. Entrar en un lugar valiéndose de escalas.

2. Trepar por una gran pendiente $\mathrm{o}$ a una gran altura.

Las entradas del DLE (2014) son similares:

1. tr. Entrar en una plaza fuerte u otro lugar valiéndose de escalas.

2. tr. Subir, trepar por una gran pendiente o a una gran altura.

Del análisis comparativo de las dos fuentes consultadas podemos concluir:

1. Que el concepto "escalada" mantiene diacrónicamente un carácter gradual de ascenso.

2. Que también ambas fuentes señalan la necesidad de recurrir a utensilios para conseguir su objetivo.

Estas conclusiones nos resultan útiles para el análisis pragmático del eufemismo "desescalada" del que podemos destacar los siguientes rasgos: 
Tabla 4. Análisis pragmático de desescalada

\begin{tabular}{|c|c|}
\hline \multirow{5}{*}{$\begin{array}{l}\text { Análisis pragmático de } \\
\text { desescalada }\end{array}$} & $\begin{array}{l}\text { 1. Implica positividad inmediata: el ascenso, la escalada con herramientas por una cumbre requiere sor- } \\
\text { tear peligros. En cambio, el descenso de la cumbre, la desescalada, implica un triunfo, la recompensa } \\
\text { del esfuerzo es la positividad con la que se desciende habiendo sido capaz de superar las dificultades, y } \\
\text { la vuelta al estado de reposo después del esfuerzo realizado. }\end{array}$ \\
\hline & $\begin{array}{l}\text { 2. Presentan y denotan un sesgo ideológico tendente a configurar en la intelección de los hablantes que } \\
\text { han podido desescalar gracias al uso de las herramientas necesarias para vencer el ascenso, esto es, } \\
\text { hacer una desescalada que optimice los resultados. Enfrentarse a un reto y conseguirlo amplía el marco } \\
\text { de optimismo en relación a las dificultades que plantea el entorno, máxime si se disponen de las herra- } \\
\text { mientas útiles (cordeles, escaleras, brújula...) que permitan mitigar la fatiga. }\end{array}$ \\
\hline & $\begin{array}{l}\text { 3. Implica superación, progreso, rebasamiento y libertad. La posibilidad de ascender por una cumbre } \\
\text { siempre supone un reto en la medida en que el entorno impone complicaciones, rebasarlas y superarlas } \\
\text { implica la libertad de salvar el reto. }\end{array}$ \\
\hline & $\begin{array}{l}\text { 4. Tiene como finalidad última trasladar una sensación de control para atenuar y contrarrestar una situa- } \\
\text { ción penosa y precaria. Gracias al dominio de la situación penosa provocada por la crisis sanitaria con } \\
\text { las herramientas sanitarias y sociales adoptadas, se puede desescalar de esa situación, contrarrestar el } \\
\text { peligro, regresar a la situación previa a la crisis, ello contribuye a que la interpretación de la realidad, la } \\
\text { cosmovisión del mundo circundante, se constituya de forma coherente y ordenada }\end{array}$ \\
\hline & 5. Se difunde masivamente por el ecosistema digital. \\
\hline
\end{tabular}

Fuente. Elaboración propia

La palabra desescalada a partir del verbo escalar se configura como un eufemismo análogo según la tabla 1. "Características comunes del vocabulario de la COVID-19 en las plataformas digitales".

Y es que el sustantivo desescalada y particularmente el verbo escalar se ha venido empleando durante la pandemia de forma análoga al uso que se le da en el deporte de montaña, por lo que le transfiere las mismas sensaciones positivas de la realidad análoga. Las imágenes conceptuales del mundo las elaboran los hablantes para comprenderlo. Escalary desescalar se utilizan como conceptos aplicados a la vida y permite a los hablantes recrear la realidad como una gigantesca aventura en la que hay que minimizar el riesgo y apostar por la superación.

Por último, como es sabido, la difusión masiva de conceptos positivos promueve cosmovisiones en los hablantes que les permite recrear la realidad de forma esperanzadora.

\subsection{El concepto desconfinamiento}

De manera análoga a lo señalado para el vocablo desescalada, partiremos aquí del sustantivo confinamiento, que nos remite al verbo confinar al que añadiremos el prefijo "des-".

El Diccionario Enciclopédico Universal en papel (1990) no recoge el verbo confinar, pero sí el sustantivo confinación o confinamiento y lo define como: 
1. Acción y efecto de confinar

2. FOR: pena consistente en relegar al condenado a cierto lugar seguro para que viva en libertad, pero bajo la vigilancia de las autoridades

También se refiere al adjetivo confinado/a como:

1. Desterrado

2. FOR: el que sufre la pena de confinamiento

Y si consultamos el DLE en línea (2014), el verbo confinar contiene las siguientes acepciones:

1. adj. Dicho de una persona: Condenada a vivir en una residencia obligatoria. U. t. c. s.

2. m. y f. Der. Persona que sufre la pena de confinamiento.

Por tanto, liberar a alguien de un destierro es el sentido pragmático que aparece ligado a la concepción semántica de desconfinar.

Del análisis comparativo de las dos fuentes consultadas podemos concluir:

1. Que el concepto "confinamiento" aparece en ambas fuentes próximo a "castigo".

2. Que el Diccionario Universal Enciclopédico ofrece una riqueza de matices que se concretan en la necesidad de supervisión de la pena por parte de las autoridades, y por incluir el adjetivo "confinado" alusivo a un destierro, que en el DEL no aparece.

Estas conclusiones nos resultan útiles para al análisis pragmático del eufemismo "desescalada" del que podemos destacar los siguientes rasgos:

Tabla 5. Análisis pragmático de desconfinamiento

\begin{tabular}{|c|c|}
\hline \multirow{5}{*}{$\begin{array}{l}\text { Análisis pragmático de } \\
\text { desconfinamiento }\end{array}$} & $\begin{array}{l}\text { 1. Implica positividad inmediata, se refiere a una liberación en lo que concierne a la supresión del esta- } \\
\text { do de alarma, que la ciudadanía vivió de forma similar a un proceso carcelario. }\end{array}$ \\
\hline & $\begin{array}{l}\text { 2. Presenta y denota un sesgo ideológico a favor de quienes posibilitan el desconfinamiento. Si confinar } \\
\text { es sinónimo de encarcelar, de recluir bajo la vigilancia de las autoridades con la potestad inclusive } \\
\text { de imponer multas, el desconfinamiento implica la liberación de ese proceso carcelario que unila- } \\
\text { teralmente se le atribuye a las leyes impuestas que permiten desconfinar levantando la situación de } \\
\text { restricción de la libertad y la vigilancia del confinando. Todo ello tiende a una visión esperanzadora } \\
\text { de los resultados ya que contribuye a la formación de una cosmovisión vivencial de regreso a lo ha- } \\
\text { bitual, de estabilidad. }\end{array}$ \\
\hline & $\begin{array}{l}\text { 3. Implica una superación, progreso, y libertad ya que supone el rebasamiento y la superación de la } \\
\text { condena y del destierro. }\end{array}$ \\
\hline & $\begin{array}{l}\text { 4. Tiene como finalidad trasladar una sensación de control para atenuar y contrarrestar una situación } \\
\text { penosa y precaria ya que supone poner fin a una situación atípica, gracias a la adición del prefijo } \\
\text { "des-" y su sentido genuino de "volver a una situación o estado anterior", es decir, poner fin a la pre- } \\
\text { cariedad. }\end{array}$ \\
\hline & 5. Se difunde masivamente por el ecosistema digital. \\
\hline
\end{tabular}

Fuente. Elaboración propia 
La palabra desconfinamiento según la tabla 1. "Características comunes del vocabulario de la COVID-19 en las plataformas digitales" es un eufemismo análogo.

\section{Contextos de uso}

La difusión de los tres vocablos empleados durante la epidemia de la COVID-19 y analizados en este trabajo, han sido universalmente los más transitados por las plataformas digitales. Por ejemplo, el verbo confinar está entre los más buscados según indica la DLE en su versión online, apartado "noticias" (Consultado 10/10/20 https://www.rae.es/noticias/ las-palabras-mas-buscadas-en-el-diccionario-durante-la-cuarentena).

Como veremos a continuación, los tres vocablos analizados se usan en diversos contextos comunicativos y noticiosos en red con posibilidad además de compartirlos por Twitter, Facebook o por WhatsApp, por lo que el alcance de su difusión a través del ecosistema digital se multiplica exponencialmente.

Tabla 6. Contextos comunicativos en red en los que se usan los tres vocablos analizados

\begin{tabular}{|c|c|}
\hline $\begin{array}{l}\text { Contexto } \\
\text { sanitario }\end{array}$ & $\begin{array}{l}\text { www.sjdhospitalbarcelona.org/es (27/05/20): “Desconfinamiento: información para las familias de pacientes con } \\
\text { un Trastorno del Espectro del Autismo Cómo enfrentarse a las salidas durante el proceso de desconfinamiento } \\
\text { que, de forma escalonada, se está llevando a cabo en todo el Estado". Disponible en https://www. } \\
\text { sjdhospitalbarcelona.org/es/desconfinamiento-informacion-para-las-familias-pacientes-con-un-trastorno-del- } \\
\text { espectro-del-autismo }\end{array}$ \\
\hline $\begin{array}{c}\text { Contexto } \\
\text { científico- } \\
\text { universitario }\end{array}$ & $\begin{array}{l}\text { Salvador, A. (21/04/20): "Una psicóloga sobre el desconfinamiento de los niños: "El acercamiento progresivo a } \\
\text { una situación "normalizada" puede aportar beneficios notables para ellos". www.noticiascyl.com. Disponible } \\
\text { en https://www.noticiascyl.com/t/1935441/valladolid-todo-valladolid-entrevista-psicologa-sobre- } \\
\text { desconfinamiento-ninos-acercamiento-progresivo-situacion-normalizada-puede-aportar-beneficios-notables } \\
\text { www.udima.es (24/06/2020): "Nueva normalidad o cómo el Covid-19 se ha apoderado de tu lenguaje". Disponible } \\
\text { en https://www.udima.es/es/articulo-covid-se-apodera-del-lenguaje-por-josep-miracle.html }\end{array}$ \\
\hline Contexto político & $\begin{array}{l}\text { Sánchez Hidalgo, E. y Álvarez, C. (29/04/20): "Estas son las cuatro fases de la desescalada en España aprobadas } \\
\text { por el Gobierno. Cada etapa durará un mínimo de dos semanas, por lo que Pedro Sánchez prevé que no se } \\
\text { podrá volver a la normalidad antes de finales de junio". www.elpais.com Disponible en https://elpais.com/ } \\
\text { sociedad/2020-04-28/estas-son-las-cuatro-fases-para-volver-a-la-normalidad-aprobadas-por-el-gobierno.html } \\
\text { Innerarity, D. (01/06/20): "El desconfinamiento o la gestión del riesgo". https://www.noticiasdegipuzkoa.eus/ } \\
\text { opinion/tribuna-abierta/2020/06/01/desconfinamiento-o-gestion-riesgo/1033886.html }\end{array}$ \\
\hline $\begin{array}{l}\text { Contexto } \\
\text { comunicativo- } \\
\text { metalingüístico }\end{array}$ & $\begin{array}{l}\text { ABC (04/05/20): “La RAE estudia incorporar en el diccionario palabras como desescalada, coronavirus o } \\
\text { desconfinamiento". https://www.abc.es/cultura/abci-estudia-incorporar-diccionario-palabras-como- } \\
\text { desescalada-coronavirus-o-desconfinamiento-202005042157_video.html } \\
\text { Pérez De Tudela, A. (05/05/20): "Desconfinamiento"https://www.diariojaen.es/opinion/articulistas/ } \\
\text { desconfinamiento-JD7104957 } \\
\text { Camps, M. (01/05/20): "Estas son las palabras de la pandemia que la RAE estudia incorporar al diccionario". } \\
\text { https://www.lavanguardia.com/cultura/20200501/48874892519/reyes-rae-pleno-academico.html }\end{array}$ \\
\hline $\begin{array}{l}\text { Contexto } \\
\text { deportivo }\end{array}$ & $\begin{array}{l}\text { https://www.marca.com/ (21/04/20): "Desescalada: de no recomendable a válido para la RAE en dos semanas". } \\
\text { https://www.marca.com/tiramillas/2020/04/21/5e9eb40f46163ff3918b45b2.html }\end{array}$ \\
\hline
\end{tabular}

Fuente. Elaboración propia 


\section{La Real Academia Española y el ecosistema digital}

Por lo demás, la propia institución lingüística RAE recoge esta pujanza del ecosistema digital, y en este sentido podemos destacar diversas publicaciones a través de su página web, a la vez que resuelve múltiples consultas vía Twitter en torno a la multiplicidad de estas y otras palabras.

Así lo evidencia, en primer lugar, la noticia publicada por el DLE "Las palabras más buscadas en el diccionario durante la cuarentena" con fecha 07/04/2020 en la que se hace eco de las múltiples visitas recibidas en el mes de abril en relación con conceptos analizados como confinar o confinado:

Pandemia, cuarentena, confinar, resiliencia, epidemia, virus, triaje o cuidar son algunas de las palabras más buscadas en el Diccionario de la lengua española (DLE) durante el último mes, en el que se han recibido más de 84 millones de visitas (casi 3 millones diarios). Los términos relacionados con la crisis del COVID-19 que generan más visitas al DLE indican una tendencia informativa clara: la gente quiere saber los significados que acompañan a esta nueva realidad. Pero también registran que existe un anhelo de palabras de aliento o que ofrezcan seguridad. Es por ello que, junto a confinado, morgue o moratoria, nos encontramos palabras como médico, inocuo, remitir, solidaridad, esperanza, altruismo o resistir. Todas ellas, tanto las que tienen una connotación negativa como positiva en estos tiempos, copan los primeros puestos en las consultas del último mes.

En segundo lugar, también se han puesto en marcha proyectos como "«Que las letras te acompañen»: la iniciativa de la RAE en redes sociales para compartir palabras que reconfortan” y el hashtag (o etiqueta) \#QueLasLetrasTeAcompañen publica esta iniciativa con la finalidad "compartir las palabras que nos acompañan en estos tiempos difíciles y que nos reconfortan ante la incertidumbre". Se trata de compartir por orden alfabético a través de las redes sociales palabras reconfortantes y consoladoras.

Como vemos, en fin, existen puntos convergentes del espíritu de la RAE con nuestro trabajo en dos líneas básicas: en el uso del ecosistema digital, (también la NGLE y ASALE) y en la línea argumental que hemos desarrollado que considera la búsqueda y el hecho de que el uso de la terminología específica novedosa de la ciudadanía en medio de esta crisis sanitaria persigue crear un marco de seguridad sobre el que edificar una cosmovisión vivencial, esperanzadora y emocional más favorable.

\section{Conclusiones}

La crisis de la pandemia de la COVID-19 ha provocado que se precise de renovados conceptos, si bien ya asentados en campos léxicos técnicos y especializados, que amplíen los estándares comunicativos con el fin de implementar los retos que plantea. Precisamente se ha generalizado el empleo de conceptos fuera de lo común gracias a la sociedad en red y a la comunicación virtual en la que la digitalización de la información y las aplicaciones de las plataformas asociadas a la comunicación han desempeñado un papel fundamental no solo como creadoras de opinión, sino como generadores y difusores de nuevos signos-tipo ejemplares. 
Este trabajo ofrece además una implementación del marco teórico, lingüístico y significativo de la generación de esos signos-tipo así como sus derivadas semánticas y pragmáticas, y evalúa las posibilidades de su lexicalización a raíz particularmente de la convergencia de una sociedad digitalizada en el origen de la emergencia sanitaria, con la introducción y el manejo de una multiplicidad de plataformas comunicativas.

Mostramos también que mediante el uso del ecosistema digital los receptores de información se convierten al mismo tiempo en transmisores de la misma, y de esta suerte inciden en el proceso de lexicalización de los conceptos novedosos en virtud de su veloz transmisión cooperante.

También exploramos una tipología de procesos clasificatorios basados en el origen diverso de las palabras clave que simultanean los hablantes en distintas plataformas digitales de una forma masiva ocasionada por la evolución -cada vez más vertiginosa hacia una sociedad en red-, que no escapa a la atenta mirada de las autoridades e instituciones lingüísticas.

Del mismo modo, la investigación también sugiere la implementación del esbozo de un corpus léxico específico a partir del estudio detallado de signos-tipo concretos útiles como modelos paradigmáticos y ejes axiales para una taxonomía propia.

Todo ello resulta especialmente relevante en medio de una crisis sanitaria súbita y mundial habida cuenta de la conexión entre la intelección que se origina a partir de las imágenes conceptuales y la cosmovisión de los hablantes y los provee de una explicación coherente, sistemática y esperanzadora del mundo que le rodea.

En general, del resultado de este análisis se desprende una intelección vivencial y emocional positiva derivada del uso de conceptos eufémicos que aparecen durante la crisis sanitaria, y referidos tanto a los componentes esenciales de la realidad como a las leyes y procesos que los configuran.

\section{Referencias bibliográficas}

$A B C$ (04/05/2020). "La RAE estudia incorporar en el diccionario palabras como desescalada, coronavirus o desconfinamiento". Disponible en https://www.abc.es/cultura/abci-estudia-incorporar-diccionario-palabras-comodesescalada-coronavirus-o-desconfinamiento-202005042157_video.html

Acero, J. J., De Bustos Guadaño, E. y Quesada Casajuana, D. (1989). Introducción a la filosofía del lenguaje. Madrid: Cátedra. Aristóteles (1982). Metafísica de Aristóteles. Edición trilingüe por Valentín García Yebra. Libro IV, 297-2, 1003b. Madrid: Gredos.

Asociación de Academias de la Lengua Española (ASALE). Disponible en https:/ /www.asale.org/

Austin, J. L. (1975). Ensayos Filosóficos. Madrid: Revista de Occidente.

Bandrés, E., Badillo, M. y Ramos, R. (2018). “Noticias falsas, manipulación informativa e infopolución”, en: Carmen Marta Lazo (ed. lit.), Calidad informativa en la era de la digitalización: fundamentos profesionales VS infopolución. Madrid: Dykinson, pp. 155-172. doi: https://doi.org/10.2307/j.ctv9zchsb.13 
Bonhomme, M., De la Torre, M. y Horak, A. (2012). Études pragmatico-discursives sur leuphémisme. Estudios pragmáticodiscursivos sobre el eufemismo. New York: Peter Lang. doi:10.3726/978-3-653-01931-5/7

Camps, M. (01/05/20). "Estas son las palabras de la pandemia que la RAE estudia incorporar al diccionario". www. lavanguardia.com Disponible en https://www.lavanguardia.com/cultura/20200501/48874892519/reyes-rae-plenoacademico.html

Chamizo Domínguez, P. J. (2004). "La función social y cognitiva del eufemismo y del disfemismo". Panace@. Boletín de Medicina y Traducción, 15 (V), pp. 45-51. Disponible en https://www.tremedica.org/wp-content/uploads/n15_ Panacea15_marzo2004.pdf

Chomsky, N. (1975). “La naturaleza formal del lenguaje”, en: E. H. Lenneberg (ed.), Fundamentos biológicos del lenguaje. Madrid: Alianza, pp. 439-487.

Chomsky, N. (1992). El lenguaje y los problemas del conocimiento: conferencias de Managua 1, Volumen 1. Madrid: Visor.

Coseriu, E. (1962). Teoría del lenguaje y lingüística general. Madrid: Gredos.

Ferrater Mora, J. (1981). Diccionario de Filosofía. Madrid: Alianza Diccionarios, $3^{\mathrm{a}} \mathrm{ed}$.

Frege, G. (1971). Estudios sobre semántica. Barcelona: Ariel.

Gadamer, H. G. (1998). El giro hermenéutico. Madrid: Cátedra.

González Quevedo, M. (2019). “Una aproximación al eufemismo y el disfemismo en la Traducción Audiovisual”. Revista de lenguas para fines específicos, 25.2, pp. 58-74. doi: http://dx.doi.org/10.20420/rlfe.2019.286

Hempel, C. G. (1966). Positivismo lógico. México: F.C.E.

Innerarity, D. (01/06/20). "El desconfinamiento o la gestión del riesgo". www.noticiasdegipuzkoa.eus Disponible en https:// www.noticiasdegipuzkoa.eus/opinion/tribuna-abierta/2020/06/01/desconfinamiento-o-gestion-riesgo/1033886.html

Leech, G. (1977). Semántica. Traducción de Juan Luis Tato G. Espada. Madrid: Alianza Editorial.

Lledó, E. (2015). El silencio de la escritura. Barcelona: Austral, $3^{\mathrm{a}} \mathrm{imp}$.

Ogden, C. K. y Richardsen, I. A. (1923). The Meaning of Meaning, Harcourt Brace \& Co.

Palmer, R. E. (2002). ¿Qué es la hermenéutica? Teoría de la interpretación en Schleiermacher, Dilthey, Heidegger y Gadamer. Madrid: Arco/Libros, S. L.

Pérez De Tudela, A. (05/05/20). "Desconfinamiento". www.diariojaen.es Disponible en https://www.diariojaen.es/ opinion/articulistas/desconfinamiento-JD7104957

Platón (1970). Cartas. Traducción de Margarita Toranzo. Instituto de Estudios Políticos, reimp. de la 1a ed. de 1954. Platón. Carta VII. 342a 7-343b 5.

Quine, W. V. O. (1962). Desde un punto de vista lógico. Barcelona: Ariel.

Ramos Gil, Y. y Fontenla Pedreira, J. (2016). "El lenguaje: interacción del periodismo y la comunicación. ¿Es posible un nuevo contexto?”, en: José Rúas Araújo (Coord.), et al., De los medios y la comunicación de las organizaciones a las redes 
de valor, XESCOM. Red Internacional de Investigación de Gestión de la Comunicación, pp. 36-51. Disponible en https:// xescom2016.files.wordpress.com/2017/01/documento-xescom.pdf

Real Academia Española y Asociación de Academias de la Lengua Española (2014). Diccionario de la lengua española, 23a edición. Barcelona: Espasa Libros. (DLE). Disponible en http://dle.rae.es

Real Academia Española y Asociación de Academias de la Lengua Española (2009). Nueva gramática de la lengua española. Madrid: Espasa Libros. (NGLE). Disponible en http://aplica.rae.es/grweb/cgi-bin/buscar.cgi

Sádaba, J. (1980). Conocer Wittgenstein y su obra. Barcelona: DOPESA.

Salvador, A. (21/04/20). "Una psicóloga sobre el desconfinamiento de los niños: "El acercamiento progresivo a una situación "normalizada" puede aportar beneficios notables para ellos". www.noticiascyl.com. Disponible en https:// www.noticiascyl.com/t/1935441/valladolid-todo-valladolid-entrevista-psicologa-sobre-desconfinamiento-ninosacercamiento-progresivo-situacion-normalizada-puede-aportar-beneficios-notables

Sánchez Hidalgo, E. y Álvarez, C. (29/04/20). "Estas son las cuatro fases de la desescalada en España aprobadas por el Gobierno. Cada etapa durará un mínimo de dos semanas, por lo que Pedro Sánchez prevé que no se podrá volver a la normalidad antes de finales de junio". www.elpais.com Disponible en https://elpais.com/sociedad/2020-04-28/estasson-las-cuatro-fases-para-volver-a-la-normalidad-aprobadas-por-el-gobierno.html

Searle, J. (1980). Actos de habla. Madrid: Cátedra.

Stumpf, E. M. (2020). "Eufemismo: um fenômeno multifacetado no cruzamento entre língua e cultura”. Letrônica, 13(2), pp. 1-12. doi: https://doi.org/10.15448/1984-4301.2020.2.36278

VV.AA. (1990) Diccionario Enciclopédico Universal. Ediciones Castell.

Wittgenstein (1994). Tractatus Logico-Philosophicus. Barcelona: Altaya.

Wikipedia. Consultado 10/10/20. Disponible en https://es.wikipedia.org/wiki/Web_2.0

www.sjdhospitalbarcelona.org/es (27/05/20). "Desconfinamiento: información para las familias de pacientes con un Trastorno del Espectro del Autismo Cómo enfrentarse a las salidas durante el proceso de desconfinamiento que, de forma escalonada, se está llevando a cabo en todo el Estado". Disponible en https://www.sjdhospitalbarcelona.org/es/ desconfinamiento-informacion-para-las-familias-pacientes-con-un-trastorno-del-espectro-del-autismo

www.udima.es (24/06/2020). "Nueva normalidad o cómo el Covid-19 se ha apoderado de tu lenguaje”. Disponible en https://www.udima.es/es/articulo-covid-se-apodera-del-lenguaje-por-josep-miracle.html

www.marca.com (21/04/20). "Desescalada: de no recomendable a válido para la RAE en dos semanas". Disponible en https://www.marca.com/tiramillas/2020/04/21/5e9eb40f46163ff3918b45b2.html 
